\title{
Study on the Influence of Process Parameters on Grain and Phases of TC4 Ti-alloy Forging Guo-Hui QUAN ${ }^{1, a^{*}}$ and Xu-Yong ZHAO ${ }^{2, b}$ \\ ${ }^{1}$ Department of Materials Science and Engineering, Zhengzhou Technical College, Zhengzhou (450121), China. \\ ${ }^{2}$ Henan University of Animal Husbandry and Economy, Zhengzhou (450011), China. \\ aQQuanguohui2005@163.com, 'zhaoxy6868@163.com
}

Keywords: TC4 alloy, Grain, Phase, Compressor speed.

\begin{abstract}
By using the finite element software, the thermal process of TC4 Ti-alloy large die forging two beam is analyzed, the influence of billet initial heating temperature and compressor speed on the distribution of grain and phase is revealed. The research shows that fine and uniform microstructure will be obtained when the billet initial heating temperature is $980^{\circ} \mathrm{C}$ and at the same time compressor speed scheme of two straight ladder variable loading is used.
\end{abstract}

\section{Introduction}

TC4 Ti-alloy (nominal component Ti-6A1-4V) is a kind of $(\alpha+\beta)$ two phase titanium alloy, which has a good process plastic, superplastic, welding and corrosion resistance etc. So it is widely used in aviation, aerospace, chemical industry and other industries [1-3]. During the high temperature forging process of TC4 Ti-alloy, dynamic recrystallization will occur, and new grains will generate. The evolution of microstructure will largely determine the macro mechanical properties of the forging. Because the occurrence of dynamic recrystallization is associated with forging temperature and deformation in the process, the dynamic recrystallization grain size can be controlled by using different deformation parameters of thermal process, and the microstructure can be refined. It is an important method to improve the mechanical properties of TC4 Ti-alloy forging. The study shows that the dynamic recrystallization grain size and the percentage of recrystallization grains are mainly determined by the temperature, strain and strain rate of the deformation and cooling process, in addition to the original grain size and the content of trace elements. So the effects of initial heating temperature and press speed on the microstructure of the billet are studied.

\section{Test}

\section{Test Materials.}

Basic dimensions of TC4 Ti-alloy large forging two beam are $3512 \mathrm{~mm} \times 138 \mathrm{~mm} \times 276 \mathrm{~mm}$, volume is about $47861890 \mathrm{~mm}^{3}$, and the forging process is carried out on the $800 \mathrm{MN}$ hydraulic press.

\section{Test Scheme.}

In the temperature range of $950^{\circ} \mathrm{C}$ to $990^{\circ} \mathrm{C}, 950^{\circ} \mathrm{C}, 960^{\circ} \mathrm{C}, 970{ }^{\circ} \mathrm{C}, 980^{\circ} \mathrm{C}$ and $990^{\circ} \mathrm{C}$ are selected as initial heating temperature of the billet. And compressor speed is used five kinds: $4 \mathrm{~mm} / \mathrm{s}, 8 \mathrm{~mm} / \mathrm{s}$, $12 \mathrm{~mm} / \mathrm{s}, 16 \mathrm{~mm} / \mathrm{s}$ and $20 \mathrm{~mm} / \mathrm{s}$ in the first fire. Parameters are shown in Tab.1.Because there are many factors in the selection, the selection and setting of the initial heating temperature of billet and compressor speed in the second fire are determined according to the simulation results of the first fire, in order to reduce the number of simulation tests. 
Tab.1 Design of simulation test parameters in the first fire

\begin{tabular}{cccccc}
\hline Test number & $\begin{array}{c}\text { Blank } \\
\text { temperature } \\
\left({ }^{\circ} \mathrm{C}\right)\end{array}$ & $\begin{array}{c}\text { Compressor } \\
\text { speed } \\
(\mathrm{mm} / \mathrm{s})\end{array}$ & Test number & $\begin{array}{c}\text { Blank } \\
\text { temperature }\end{array}$ & $\begin{array}{c}\text { Compressor } \\
\text { speed } \\
(\mathrm{mm} / \mathrm{s})\end{array}$ \\
\hline 1 & 950 & 4 & 14 & 970 & 16 \\
\hline 2 & 950 & 8 & 15 & 970 & 20 \\
3 & 950 & 12 & 16 & 980 & 4 \\
4 & 950 & 16 & 17 & 980 & 8 \\
5 & 950 & 20 & 18 & 980 & 12 \\
6 & 960 & 4 & 19 & 980 & 16 \\
7 & 960 & 8 & 20 & 980 & 20 \\
8 & 960 & 12 & 21 & 990 & 4 \\
9 & 960 & 16 & 22 & 990 & 8 \\
10 & 960 & 20 & 23 & 990 & 12 \\
11 & 970 & 4 & 24 & 990 & 16 \\
12 & 970 & 8 & 25 & 990 & 20 \\
13 & 970 & 12 & & & \\
\hline
\end{tabular}

\section{Test results and Discussion}

The effect of initial heating temperature on grain and phases. The forging temperature, the average grain size, $\alpha$ phase volume fraction and the standard deviation are shown in Fig. 1 in the simulation test of the first fire (before cooling). It can be seen from the Fig.1, with the increase of temperature, the average grain size of the forging maintains an upward trend on the whole, but at $980^{\circ} \mathrm{C}$, the average grain size suddenly decreases, then suddenly increases. The grain size also increases, which is mainly due to the increase of temperature, grain boundary activity and the grain boundary movement rate, so that the grain growth rate increases.
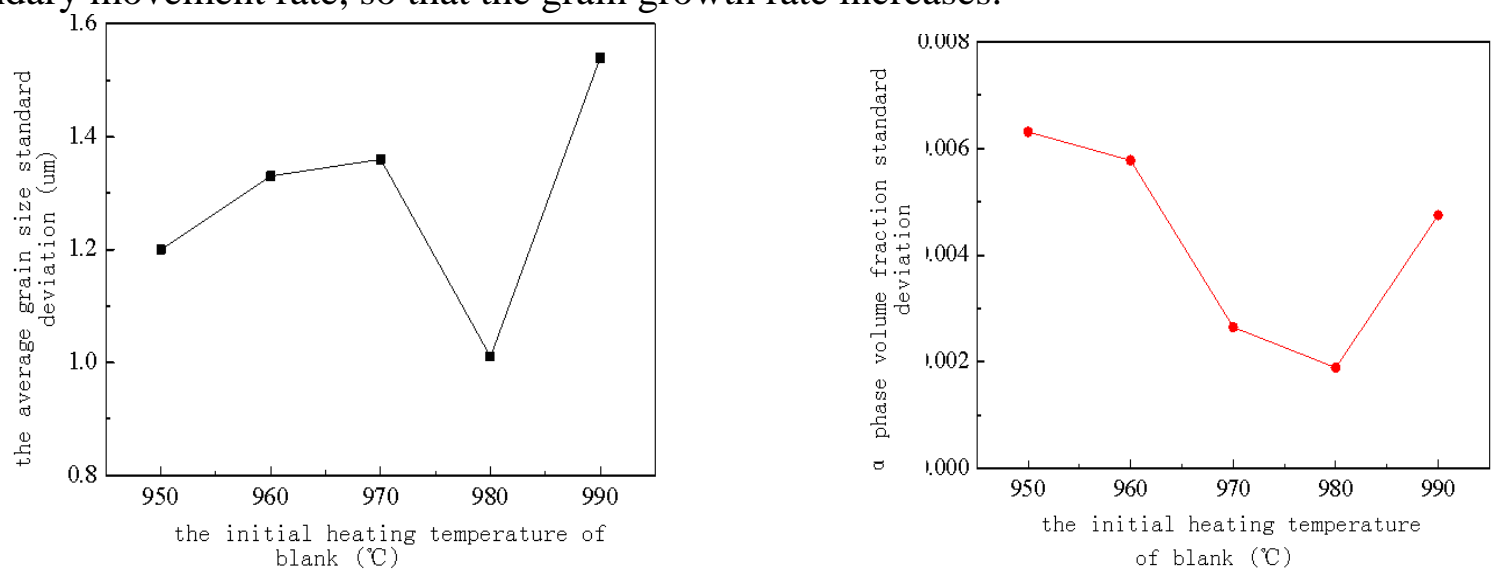

Fig. 1 The average grain size and $\alpha$ phase volume fraction standard deviation in different temperatures

When the temperature is $980^{\circ} \mathrm{C}$, the average grain size standard deviation, $\alpha$ phase volume fraction standard deviation are both taken to the minimum value, which shows that the forging can 
get the most uniform grain distribution and phase distribution. At $980^{\circ} \mathrm{C}$, the different phenomenon analysis which is not the same as change trend is due to the appearance of local near $\beta$ forging in the forging process(The forging is carried out at $15^{\circ} \mathrm{C}$ below the phase change point)[4-6]. It is because that the forging temperature decreases in the process of billet transport and the mold space travel, the surface temperature will be reduced to $750^{\circ} \mathrm{C}$. But the core temperature decreases slowly, and energy convert in the forging process. So when a local temperature rises to about $975^{\circ} \mathrm{C}$, a near $\beta$ forging will occur and the fine and uniform grain will be got.

The effect of compressor speed on grain size and phase. Because better organization can be obtained at the initial billet heating temperature of $980^{\circ} \mathrm{C}$, the second fire billet heating temperature should be set directly for $980^{\circ} \mathrm{C}$.Compressor speed is used five kinds: $4 \mathrm{~mm} / \mathrm{s}, 8 \mathrm{~mm} / \mathrm{s}, 12 \mathrm{~mm} / \mathrm{s}$, $16 \mathrm{~mm} / \mathrm{s}$ and $20 \mathrm{~mm} / \mathrm{s}$ in the second fire. Test parameters are set as shown in Tab.2. The influence of compressor speed on the microstructure parameters in the second fire is shown in Fig.2.

Tab.2 Design of simulation test parameters in the second fire

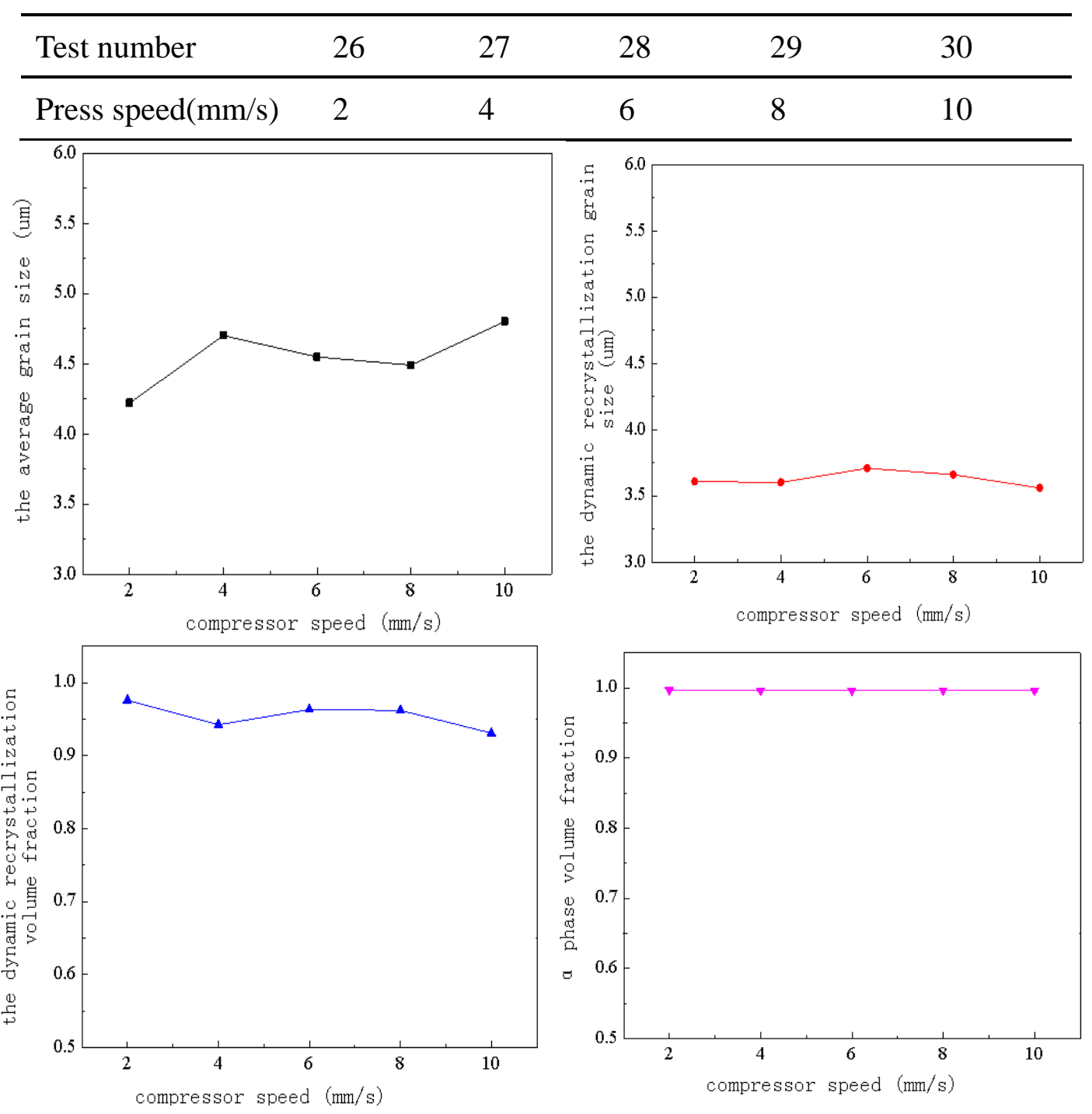

Fig. 2 The effect of compressor speed on grain size and phase in the second fire

As can be seen from Fig.2, the effect of compressor speed on $\alpha$ phase volume fraction is very small, but the dynamic recrystallization volume fraction has different results. The dynamic recrystallization volume fraction distribution in the second fire is much wider than that of the first fire, and the differences between them are also revealed. Dynamic recrystallization volume fraction decreases first and increases after, then keeps decreasing trend as compressor speed from $2 \mathrm{~mm} / \mathrm{s}$ to $6 \mathrm{~mm} / \mathrm{s}$. This is mainly because die trip is short, forging process is also short, the deformation is 
small, parts of forging region are too late to occur dynamic recrystallization or can't reach the critical strain, the dynamic recrystallization is unable to be completed in the second fire.

The uniform and fine grain and relatively uniform phase distribution are got when compressor speed is $2 \mathrm{~mm} / \mathrm{s}$. But because compressor speed is too low, forging process is relatively long, temperature decreases largely, and the temperature field distribution is not uniform, the deformation resistance increases dramatically, so as to make the mould load to 7.58 million tons. This has been close to the limit load capacity of the equipment, and it should be avoided as far as possible. When the press speed is $8 \mathrm{~mm} / \mathrm{s}$, the uniform and fine grain, more uniform temperature distribution and the moderate mold load are obtained, which are suitable for the second fire forging process.

Optimization of speed loading scheme for press. Because the blank heating temperature range is very narrow, the temperature control is not very flexible, the optimization of billet heating temperature doesn't have great practical significance. And for 800MN hydraulic machine, speed loading scheme can be very flexible. Because of the final performance of forging depends on the second heat forging process, compressor speed loading scheme in the second fire is mainly optimized.

By designing six kinds of variable load mode which include curve type, linear type, curve and linear hybrid, secondary ladder line type, three level ladder line type, three hybrid ladder type, and by simulating $2 \sim 4$ kinds of speed scheme for each speed loading mode, a total of 20 groups of simulation and optimization tests are conducted. Through statistical analysis of the simulation results, it can be obtained that the variable loading scheme can obviously improve the forging microstructure. It is shown as Fig.3.For the convenience of research, it is set to (a), (b), (c), (d) program. The optimization results which are obtained from the four optimization schemes are shown in Tab.3.
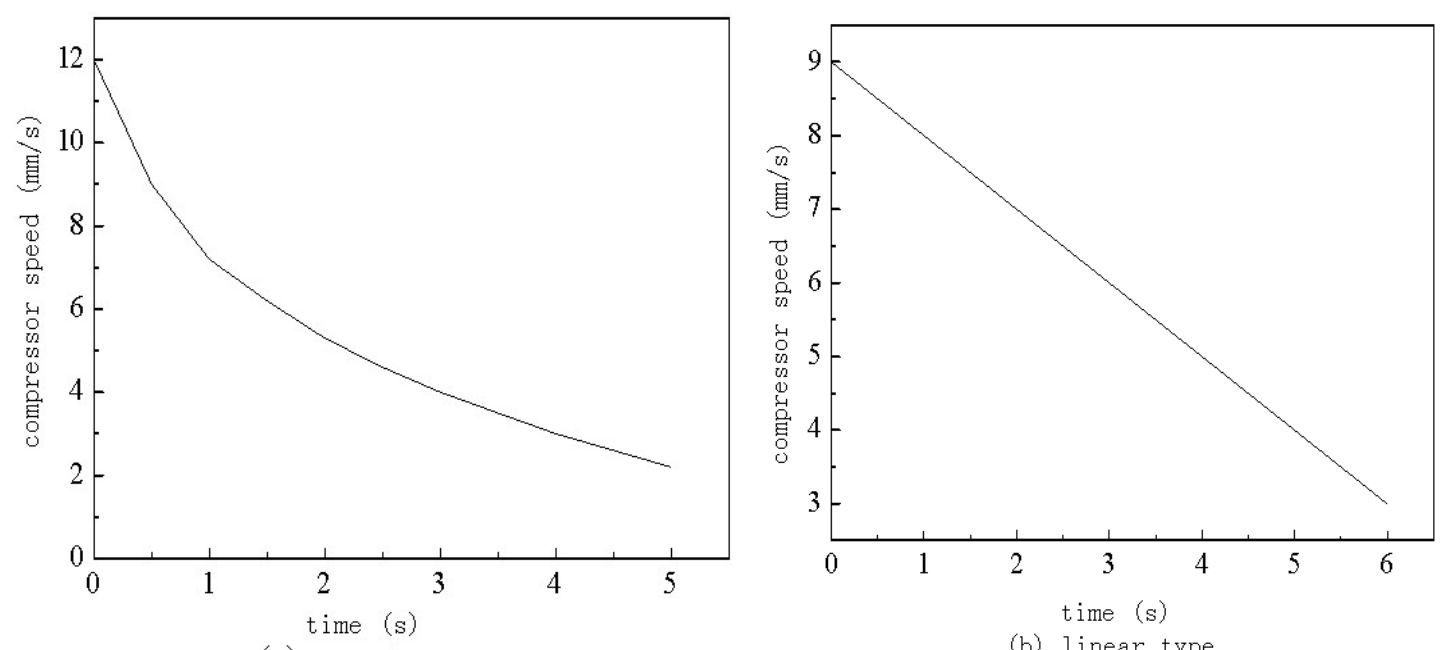

(a) curve type
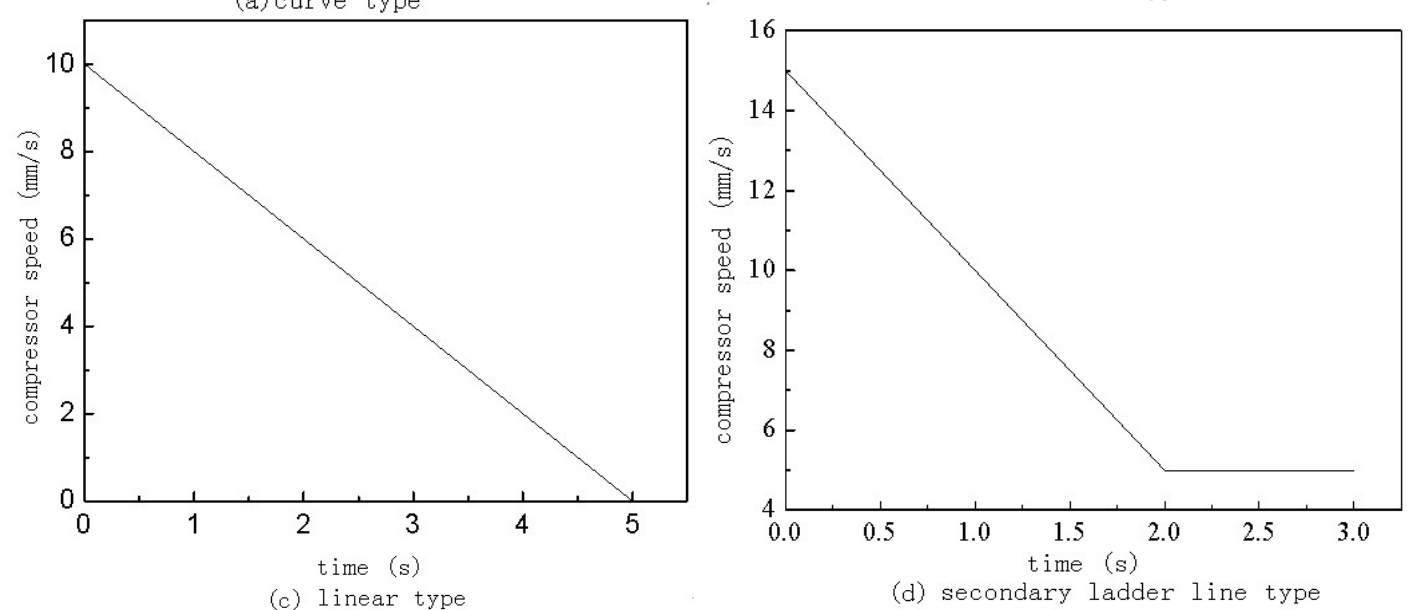

(d) secondary ladder line type

Fig.3 The optimized speed loading schemes 
It can be obtained from Tab.3 that the four group optimization schemes based on the original scheme have a better optimization effect. By using D scheme as the best plan, the minimum load, the most uniform temperature and phase distribution are obtained. But if the press speed is too fast, the deformation will be inhomogeneous and he forging structure will also be inhomogeneous.

When the press speed is slow, it is more conducive to obtain uniform organization, but the grain will be relatively bulky.

Tab.4 The optimized results obtained by the optimization method (S.D. represents the standard deviation of the previous column of data in the table)

\begin{tabular}{llllllll}
\hline & $\begin{array}{l}\text { The average } \\
\text { temperature } \\
\text { of } \\
\text { forging }\left({ }^{\circ} \mathrm{C}\right)\end{array}$ & $\begin{array}{l}\text { S.D. } \\
\left({ }^{\circ} \mathrm{C}\right)\end{array}$ & $\begin{array}{l}\text { The } \\
\text { average } \\
\text { grain } \\
\text { size }(\mu \mathrm{m})\end{array}$ & $\begin{array}{l}\text { S.D. } \\
(\mu \mathrm{m})\end{array}$ & $\begin{array}{l}\alpha \text { phase } \\
\text { volume } \\
\text { fraction }\end{array}$ & $\begin{array}{l}\text { S.D. } \\
\text { Die load } \\
\text { ten } \\
\text { thousand } \\
\text { tons) }\end{array}$ \\
\hline $\begin{array}{l}\text { Original } \\
\text { scheme }\end{array}$ & 801 & 111 & 4.49 & 3.01 & 0.996 & 0.00314 & 6.19 \\
$\begin{array}{l}\text { A scheme } \\
\text { B scheme }\end{array}$ & 809 & 101 & 4.23 & 2.56 & 0.998 & 0.00162 & 6.47 \\
C scheme & 817 & 94.9 & 4.39 & 2.88 & 0.998 & 0.00137 & 6.74 \\
D scheme & 824 & 102 & 4.42 & 2.87 & 0.998 & 0.00166 & 6.75 \\
\hline
\end{tabular}

\section{Conclusions}

(1)When the initial heating temperature of billet is $980^{\circ} \mathrm{C}$,the fine and uniform grains can be obtained. This is because the local area of the blank appears near $\beta$ forging.

(2)By using the variable speed load mode of secondary ladder line type, the small and uniform structure can be obtained. This is because the fast press speed is able to get small grain, the volume fraction of $\beta$ phase will increase.

\section{References}

[1] Wenguang Lei, Xiaonan Mao, Yafeng Lu,et al. Effects of heat treatment process on microstructure and mechanical properties of TC4-DT titanium alloy plate[J]. Heat Treatment of Metals. 2012,37(9):102-105. (In Chinese)

[2]S.Katani, F.Madadi, M.Atapour,S. Ziaei Rad. Micromechanical modelling of damage behaviour of Ti-6Al-4V[J]. Materials and Design . 2013.

[3] Ying Liu, Zhou-de Qu, Ben-xian Wang. Research development and application of Ti6AI4V alloy[J].Ordnance Material Science and Engineering, 2005,28(5):47-50. (In Chinese)

[4] Miaoquan Li, DunJun Chen, Aiming Xiong,et al. An adaptive prediction model of grain size of for the forging of Ti-6A1-4V alloy based on fuzzy neural networks[J].Journal of Materials Processing Technology, 2002, 123: 377-381. (In Chinese)

[5] G.Q. Wu,C.L. Shi,W. Sha,A.X. Sha,H.R. Jiang. Effect of microstructure on the fatigue properties of Ti-6Al-4V titanium alloys[J]. Materials and Design . 2013.

[6] Yigang Zhou, Weidong Zeng, Hanqing,et al.Effect of solution treatment on morphology of near $\beta$ forged TC21alloy[J].The Chinese Journal of Nonferro Yu us Metals, 2010,20(1):581-586. (In Chinese) 